\title{
Anatomia do escapo e rizoma de espécies brasileiras de Bulbostylis Kunth (Cyperaceae) ${ }^{1}$
}

\author{
ANA PAULA PRATA ${ }^{2,6}$, NANUZA LUIZA DE MENEZES ${ }^{3}$, SOLANGE C. MAZZONI-VIVEIROS ${ }^{4}$, \\ MARIA DAS GRAÇAS L. WANDERLEY ${ }^{4}$ e WILLIAM WAYT THOMAS ${ }^{5}$
}

(recebido: 23 de março de 2006; aceito: 12 de abril de 2007)

\begin{abstract}
Scape anatomy and rhizome of Brazilian species of Bulbostylis Kunth (Cyperaceae)). Bulbostylis Kunth (subfamily Cyperoideae) comprises approximately 150 species with centers of distribution in South America and Africa. The anatomy of the scapes was studied in 40 species of Bulbostylis. The characters found to be of taxonomic value in the key species are: the shape of the scape in transverse section, the presence of ribs and furrows, the aspect of the epidermal cells and stomata, the shape of the cortical sclerenchymatous strands, the number of vascular unit, a fistulose medulla, and the occurrence of radiate parenchyma. These characters were found to be diagnostically useful at the specific level. We also show that the scape should be considered a monostele. The atactostele appears in the rhizome.
\end{abstract}

Key words - atactostele, Kranz anatomy, monostele, vascular unit

RESUMO - (Anatomia do escapo e rizoma de espécies brasileiras de Bulbostylis Kunth (Cyperaceae). Bulbostylis Kunth (subfamília Cyperoideae) é um gênero neotropical, com centros de distribuição na América do Sul e África. Está representado por aproximadamente 150 espécies, das quais 44 ocorrem no Brasil, principalmente nas formações de cerrado e campo rupestre. São apresentados na chave de identificação, dados da anatomia do escapo com valor diagnóstico na delimitação específica para 40 espécies de Bulbostylis. Entre eles, destacam-se: formato do escapo em seção transversal, presença de costelas e sulcos, aspecto das células epidérmicas e estômatos, forma dos cordões esclerenquimáticos corticais, número de unidades vasculares, medula fistulosa e a ocorrência de parênquima radiado. Além disso, ressaltou-se que o escapo de Bulbostylis se trata de um monostelo, e o rizoma de um atactostelo.

Palavras-chave - anatomia Kranz, atactostelo, monostelo, unidades vasculares

\section{Introdução}

O uso da anatomia na complementação de caracteres morfológicos está se tornando cada vez mais comum, como já ressaltado por Metcalfe \& Chalk (1950) para as Angiospermas e, especialmente, para Cyperaceae por Govindarajalu (1966), Kukkonen (1967) e Metcalfe (1969). Em alguns grupos, onde a morfologia vegetativa é bastante uniforme (Poaceae, Cyperaceae), a utilização da anatomia auxiliando a taxonomia é bastante significativa (Kukkonen 1967). Em Cyperaceae esses estudos são comuns e têm revelado bons

\footnotetext{
1. Parte da tese de doutorado do primeiro autor, Programa de Pós-Graduação em Botânica da Universidade de São Paulo.

2. Universidade Federal de Sergipe, Departamento de Biologia, Campus Universitário Professor Aloísio de Campos, 49100000 São Cristóvão, SE, Brasil.

3. Universidade de São Paulo, Instituto de Biociências, Departamento de Botânica, Caixa Postal 11461, 05508-900 São Paulo, SP, Brasil.

4. Instituto de Botânica, Divisão de Fitotaxonomia, Caixa Postal 4005, 01061-970 São Paulo, SP, Brasil.

5. The New York Botanical Garden, Bronx, 10458-5126, New York, EUA.

6. Autor para correspondência: apprata@yahoo.com.br
}

resultados para a identificação das espécies (Plowman 1906, Metcalfe 1969, Shepherd 1976).

Segundo Denton (1983), os dados anatômicos são freqüentemente empregados na taxonomia de Cyperus L., visando a caracterização das espécies e a determinação de relações filogenéticas. Govindarajalu (1969a) analisou sete táxons sul-indianos de Cyperus, subgênero Kyllinga (Rottb.) Suringar. As características anatômicas observadas, além de fornecerem diferenças interespecíficas, permitiram dividir as espécies em dois grupos distintos, um com folhas simétricas e outro com folhas assimétricas. Além de Cyperus, outros gêneros de Cyperaceae, como Carex (Shepherd 1976) e Fuirena (Govindarajalu 1969b), também foram objetos de estudos anatômicos.

Dentre os trabalhos anatômicos realizados com táxons brasileiros de Cyperaceae destaca-se a análise das tribos Cryptangieae (Koyama \& Maguire 1965, Vitta 2005) e Sclerieae (Koyama 1967) e dos gêneros Eleocharis (Eiten 1969), Remirea (Estelita 1992, 1993), Trilepis (Arruda \& Neves 2005), Cyperus (Araújo \& Longhi-Wagner 1997, Rodrigues \& Estelita 2003), Rhynchospora seção Tenues (Rocha 2002), 
Lagenocarpus (Silva 2000) e Hypolytrum (Alves et al. 2002).

Koyama (1965) investigou a tendência evolutiva de caracteres anatômicos vegetativos em representantes das tribos Lagenocarpeae e Sclerieae, relatando que algumas observações anatômicas podem ter considerável importância taxonômica na separação das tribos relacionadas.

Standley (1990) avaliou a utilidade de caracteres anatômicos na sistemática e filogenia de Carex, sugerindo que estes caracteres são potencialmente de maior importância em estudos filogenéticos no nível infragenérico e entre seções distintas.

De acordo com Metcalfe (1969), os caracteres anatômicos importantes e significativos para Cyperaceae são aqueles fornecidos pela epiderme foliar, pela seção transversal das folhas e do órgão por ele denominado de caule.

A utilização dos termos caule e escapo para representantes das Cyperaceae é bastante controversa. Segundo Fontquer (1989), o escapo é um órgão aéreo que se origina de rizomas, cormos ou bulbos. Em Cyperaceae, de acordo com Alves (2000), representa um entrenó distendido e não foliáceo. Em Lagenocarpus há vários entrenós, segundo Silva (2000) e Vitta (2005). Segundo Alves et al. (2002), eixos reprodutivos não foliáceos representam um alongamento do entrenó, de acordo com a definição clássica do termo escapo, e podem ser encontrados entre espécies dos gêneros Cyperus L., Eleocharis R. Br. e Rhynchospora Vahl. Acredita-se, assim, que para as espécies estudadas, o emprego do termo escapo é o mais adequado, pois as estruturas presentes se enquadram nas definições encontradas em Fontquer (1989) e Alves (2000).

O escapo em Cyperaceae também foi denominado de colmo ("culm") por Kukkonen (1967), Shepherd (1976) e Govindarajalu (1981). Estudos referentes à anatomia desse órgão são escassos, apesar dessas análises fornecerem caracteres que podem auxiliar na classificação infragenérica. Destacam-se os de Shepherd (1976), que estudou a anatomia do escapo em 15 táxons de Carex, além da anatomia foliar de 22 espécies pertencentes a 15 seções. Kukkonen (1967) analisou a anatomia da folha e escapo de Uncinia Pers., enquanto Govindarajalu (1981) estudou a anatomia vegetativa de um novo táxon (Lipocarpha rayleana Govindarajalu), incluindo detalhes da folha, do escapo e da raiz.

O tipo de estelo presente na estrutura primária caulinar das monocotiledôneas é o chamado atactostelo, composto por feixes que aparecem internamente à endoderme como unidades independentes dispersos de forma irregular pelo tecido parenquimático (Brebner 1902,
Foster \& Gifford 1959, Smith 1955). O caule da maioria das monocotiledôneas não apresenta crescimento secundário, mas algumas espécies desenvolvem caules espessos em conseqüência da formação de um meristema de espessamento secundário (Sajo \& Castro 2003).

Segundo Soros \& Bruhl (2000), em Cyperaceae há quatro tipos distintos de anatomia foliar $\mathrm{C}_{4}$ ("clorocyperóide, fimbristylóide, eleocharóide e rhynchosporóide") que diferem na posição do periciclo (denominado pelos autores de Photosynthetic Carbon Reduction - PCR), presença ou ausência de bainha vascular parenquimática e posição dos elementos de vaso do metaxilema em relação ao PCR. A ocorrência de algumas dessas variantes anatômicas $\mathrm{C}_{4}$ nos gêneros Bulbostylis, Eleocharis e Rhynchospora também foi citada pelos referidos autores.

Dentre os estudos anatômicos realizados com o rizoma de representantes de alguns gêneros de Cyperaceae, destacamos os de Eiten (1969) com Eleocharis, Sharma \& Mehra (1972) com Fimbristylis, Govindarajalu (1974) com Cyperus e Estelita (1999) com Cyperus giganteus. Além disso, Silva (2000) investigou quais tecidos estariam envolvidos no espessamento do rizoma em nove espécies de Lagenocarpus de campos rupestres, visando esclarecer a natureza desse espessamento, se primária ou secundária.

O gênero Bulbostylis Kunth é constituído por aproximadamente 150 espécies distribuídas nas regiões tropicais e subtropicais de ambos hemisférios. É particularmente abundante na África tropical e América do Sul (Lye 1996). Com registro de 44 espécies no Brasil (Prata 2004). É um gênero constituído por plantas heliófilas, crescendo principalmente nas formações de cerrado e campos rupestres, em campos secos, entre pedras, ou em solos inundáveis.

Bulbostylis está inserido na subfamília Cyperoideae, tribo Abildgaardieae (Goetghebeur 1986, Bruhl 1995). Na análise supragenérica das Cyperaceae, baseada no seqüenciamento do gene $r b c \mathrm{~L}$ e em dados morfológicos (Muasya et al. 2000), Bulbostylis faz parte de um clado que compreende, também, os gêneros Abildgaardia, Arthrostylis, Fimbristylis e Nemum.

Os trabalhos anatômicos com Bulbostylis são escassos na literatura. Até o momento, são conhecidos apenas os estudos de Pfeiffer (1927), Govindarajalu (1966) e Metcalfe (1971). Segundo esses autores, os padrões epidérmicos da lâmina foliar, incluindo forma $\mathrm{e}$ arranjo das paredes das células intercostais, células subsidiárias do estômato e células interestomatais, cutícula, papilas, tricomas tectores e corpos silicosos, demostraram utilidade na identificação e classificação 
dessas espécies. Além desses estudos, Oh (1992) analisou em microscopia eletrônica de varredura os padrões da epiderme foliar de alguns táxons de Cyperaceae que ocorrem na Coréia (Bulbostylis, Eriophorum, Fuirena, Kyllinga, Lipocarpha, Pycreus, Rhynchospora e Scleria), com o objetivo de testar a classificação corrente.

O presente trabalho tem como objetivos estudar espécies brasileiras de Bulbostylis, visando contribuir na definição do tipo de estelo no rizoma e no escapo, bem como levantar caracteres anatômicos do escapo que auxiliem na taxonomia do gênero.

\section{Material e métodos}

Os materiais empregados se encontram depositados nos herbários cujas siglas seguem a citação proposta por Holmgren et al. (1990), de acordo com a tabela 1.

Tabela 1. Espécies analisadas com os respectivos dados de coleta do material testemunho e sigla do herbário onde se encontram depositados.

Table 1. Analyzed species, vouchers and Herbarium acronym.

\begin{tabular}{|c|c|c|c|}
\hline Gênero & Espécie & Coletor/Número & Herbário \\
\hline \multicolumn{4}{|c|}{ Bulbostylis } \\
\hline & B. amambayensis Barros & A.P. Prata 993 & $\mathrm{SP}$ \\
\hline & B. capillaris (L.) C.B. Clarke & A.P. Prata 994 & $\mathrm{SP}$ \\
\hline & B. carajana Kral \& M. T. Strong & O.C. Nascimento 526 & MG \\
\hline & B. conifera (Kunth) C.B. Clarke & A.P. Prata 1048 & $\mathrm{SP}$ \\
\hline & B. consanguinea (Kunth) C.B. Clarke & A.P. Prata 843 & $\mathrm{SP}$ \\
\hline & B. conspicua (Boeck.) H. Pfeiff. & H.F. Leitão 17192 et al. & UEC \\
\hline & B. distichoides Lye & A.L. Costa \& G.M. Barroso s.n. & ALCB 07250 \\
\hline & B. edwalliana (Boeck.) Prata \& López & A. Loefgren \& G. Edwall 2038 & $\mathrm{SP}$ \\
\hline & B. eleocharoides Kral \& M.T. Strong & A.P. Prata 1072 et al. & $\mathrm{SP}$ \\
\hline & B. emmerichiae T. Koyama & R. Romero 4030 et al. & $\mathrm{SP}$ \\
\hline & B. fasciculata Uittien & A.P. Prata $904 \&$ L.P. Belmont & $\mathrm{SP}$ \\
\hline & B. fendleri C.B. Clarke & H.F. Leitão-Filho 1837 et al. & UEC \\
\hline & B. fimbriata (Nees) C.B. Clarke & A.P. Prata 812 & $\mathrm{SP}$ \\
\hline & B. hirtella (Schrad. ex Schult) Urb. & A.P. Prata $893 b$ & $\mathrm{SP}$ \\
\hline & B. jacobinae (Steud.) Lindm. & R. Kral 75867 \& M.G. Wanderley & $\mathrm{SP}$ \\
\hline & B. junciformis (Kunth) C.B. Clarke & A.P. Prata 895 & $\mathrm{SP}$ \\
\hline & B. juncoides (Vahl) Kuk & A.C. Araújo 459 & $\mathrm{ICN}$ \\
\hline & B. lagoensis (Boeck.) Prata \& M.G. López & A.P. Prata 872 & SP \\
\hline & B. lanata (Kunth) Lindm. & E. Oliveira 1983 & IAN \\
\hline & B. latifolia Kral \& M.T. Strong & M.G. Wanderley 1877 \& R. Kral 75909 & $\mathrm{SP}$ \\
\hline & B. loefgrenii (Boeck.) Prata \& M.G. López & G. Eiten \& L.T Eiten 2434 & $\mathrm{SP}$ \\
\hline & B. lombardii Kral \& M. T. Strong & A.P. Prata 1055 et al. & $\mathrm{SP}$ \\
\hline & B. major Palla & J. Mattos 12511 & $\mathrm{SP}$ \\
\hline & B. nesiotis C.B. Clarke & F. Angeloni \& P.F. Neto s.n. & R 187826 \\
\hline & B. pachypoda Kral \& M.T. Strong & R. Kral 75175 \& M.G. Wanderley & SP \\
\hline & B. paradoxa (Spreng.) Lindm. & A.P. Prata 1013 & $\mathrm{SP}$ \\
\hline & B. paraensis C.B. Clarke & A.C. Brade 175982 \& A. Barbosa & $\mathrm{R}$ \\
\hline & B. scabra (Presl) C.B. Clarke & A.P. Prata 865 & $\mathrm{SP}$ \\
\hline & B. scomburgkiana (Steud.) M. T. Strong & A.P. Prata 488 & $\mathrm{SP}$ \\
\hline & B. sellowiana (Kunth) Palla & A.P. Prata 861 & $\mathrm{SP}$ \\
\hline & B. smithii Barros & L.B. Smith et al. 6889 & NY \\
\hline & B. sphaerocephala (Boeck.) C.B. Clarke & A.P. Prata 749 et al. & $\mathrm{SP}$ \\
\hline & B. splendens M.T. Strong & G.T. Prance et al. 6016 & $\mathrm{SP}$ \\
\hline & B. svensoniana Steyermark & G.F. Mensdtedt s.n. & R231942 \\
\hline & B. tenuifolia (Rudge) J.F Macbr. & J.S. Silva 624 & $\mathrm{SP}$ \\
\hline & B. truncata (Nees) M. Strong & M.A. Silva $4511 \&$ S.C. Faria & $\mathrm{SP}$ \\
\hline & B. vestita (Kunth) C.B. Clarke & A.P. Prata 552 et al. & $\mathrm{SP}$ \\
\hline & B. sp. 1 & A.P. Prata 859 & $\mathrm{SP}$ \\
\hline & B. sp.2 & R. Amado 260 & $\mathrm{SP}$ \\
\hline
\end{tabular}


Para a análise anatômica, foram feitas seções histológicas transversais do rizoma e escapo, obtidas à mão livre com auxílio de lâmina de barbear, em material previamente fixado em F.A.A em etanol 50\% (Sass 1951) e, posteriormente, estocado em etanol 70\% (Johansen 1940). Quando da ausência de material fresco foram empregadas amostras provenientes de material herborizado devidamente reidratadas.

As seções transversais obtidas foram diafanizadas em hipoclorito de sódio a $16 \%$ e submetidas ao processo de dupla coloração, com azul de astra e safranina na proporção de 9:1 (modificado de Bukatsch 1972 apud Kraus \& Arduin 1997). Lâminas permanentes e semi-permanentes foram montadas em bálsamo-do-Canadá e glicerina 50\%, respectivamente. A presença de amido foi detectada pela reação com lugol e cloreto de zinco iodado (Johansen 1940).

A terminologia adotada foi a de Metcalfe (1971), para a família Cyperaceae, e a de Cheadle \& Uhl (1948), para o formato das unidades vasculares. A classificação de Metcalfe \& Gregory (1964) foi adotada para a descrição do formato dos cordões esclerenquimáticos.

Fotomicrografias foram obtidas utilizando-se câmara Olympus C-35 AD, adaptada a um fotomicroscópio Olympus Vanox.

\section{Resultados e Discussão}

O primeiro aspecto que se pretende discutir diz respeito ao tipo de estelo observado no rizoma de Bulbostylis. Conforme já demonstrado por Menezes et al. (2005) em Cyperus papyrus L., e em outras monocotiledôneas, no rizoma de Bulbostylis o estelo é do tipo atactostelo (figuras 1-3). Nesse tipo de estelo, internamente à endoderme encontra-se o periciclo, camada geradora de tecidos vasculares quando só ocorre espessamento primário, conforme demonstrado por Van Tieghem (1898), Ogura (1972) e outros pesquisadores do século XIX e confirmado por Menezes et al. (2005). Internamente ao periciclo, observam-se numerosos feixes vasculares, constituídos de xilema e floema primários (figuras 2-3). Há dois tipos de feixes, com proto e metaxilema e proto e metafloema (traços foliares) ou apenas com metaxilema e metafloema (feixes caulinares). No entanto, o escapo, que a maioria dos autores se refere como sendo um colmo ("culm") (Govindarajalu 1966, Kukkonen 1967, Shepherd 1976) e que tem sido citado como um estelo do tipo atactostelo (Esau 1977, Fahn 1989), na realidade é formado de unidades vasculares que apresentam além do xilema e floema primários, periciclo e endoderme, portanto, não podem ser considerados feixes (Menezes et al. 2003), caracterizando a unidade do sistema vascular como sendo do tipo monostelo (figuras 4-19).
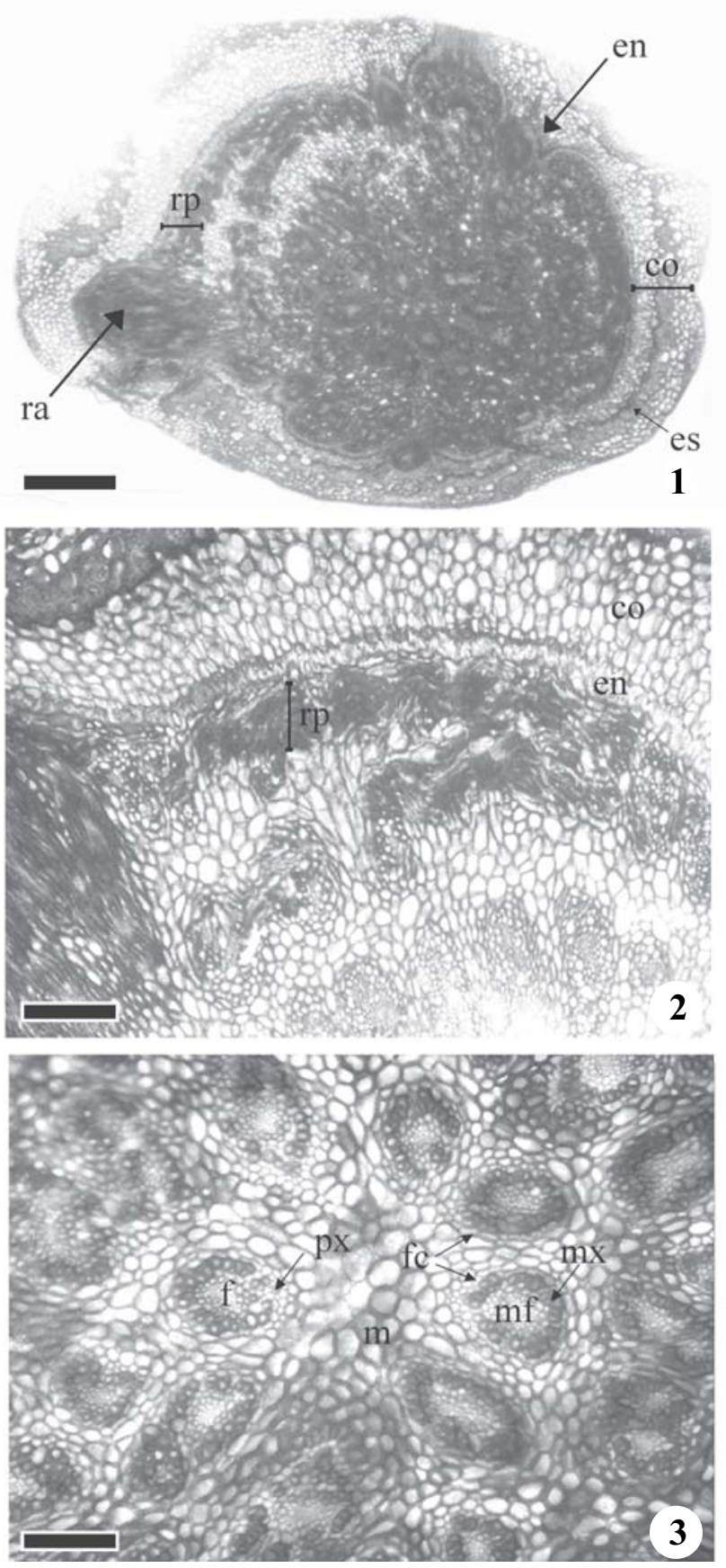

Figuras 1-3. Seção transversal do rizoma de Bulbostylis junciformis (Kunth) C.B. Clarke, com sistema vascular (estelo) do tipo atactostelo. $(\mathrm{co}=$ córtex; $\mathrm{en}=$ endoderme; $\mathrm{es}=$ esclerênquima; $\mathrm{f}=$ floema $; \mathrm{fc}=$ feixe caulinar; $\mathrm{m}=$ medula $; \mathrm{mf}=$ metafloema $; \mathrm{mx}=$ metaxilema; $\mathrm{px}=$ protoxilema; $\mathrm{ra}=$ raiz adventícia; $\mathrm{rp}=$ região pericíclica). Barra $=220 \mu \mathrm{m}(1), 90 \mu \mathrm{m}(2), 22 \mu \mathrm{m}(3)$.

Figure 1-3. Rhizome transverse section of Bulbostylis junciformis (Kunth) C.B. Clarke, with atactostele type of vascular system (stele). $($ co = cortex; en = endodermis; es = sclerenchyma; $\mathrm{f}=$ phloem; $\mathrm{fc}=$ steam bundles; $\mathrm{m}=$ medulla; $\mathrm{mf}=$ metaphloem; $\mathrm{mx}$ $=$ metaxylem $; \mathrm{px}=$ protoxylem; $\mathrm{ra}=$ adventitious root; $\mathrm{rp}=$ pericycle region). Bar $=220 \mu \mathrm{m}(1), 90 \mu \mathrm{m}(2), 22 \mu \mathrm{m}(3)$. 

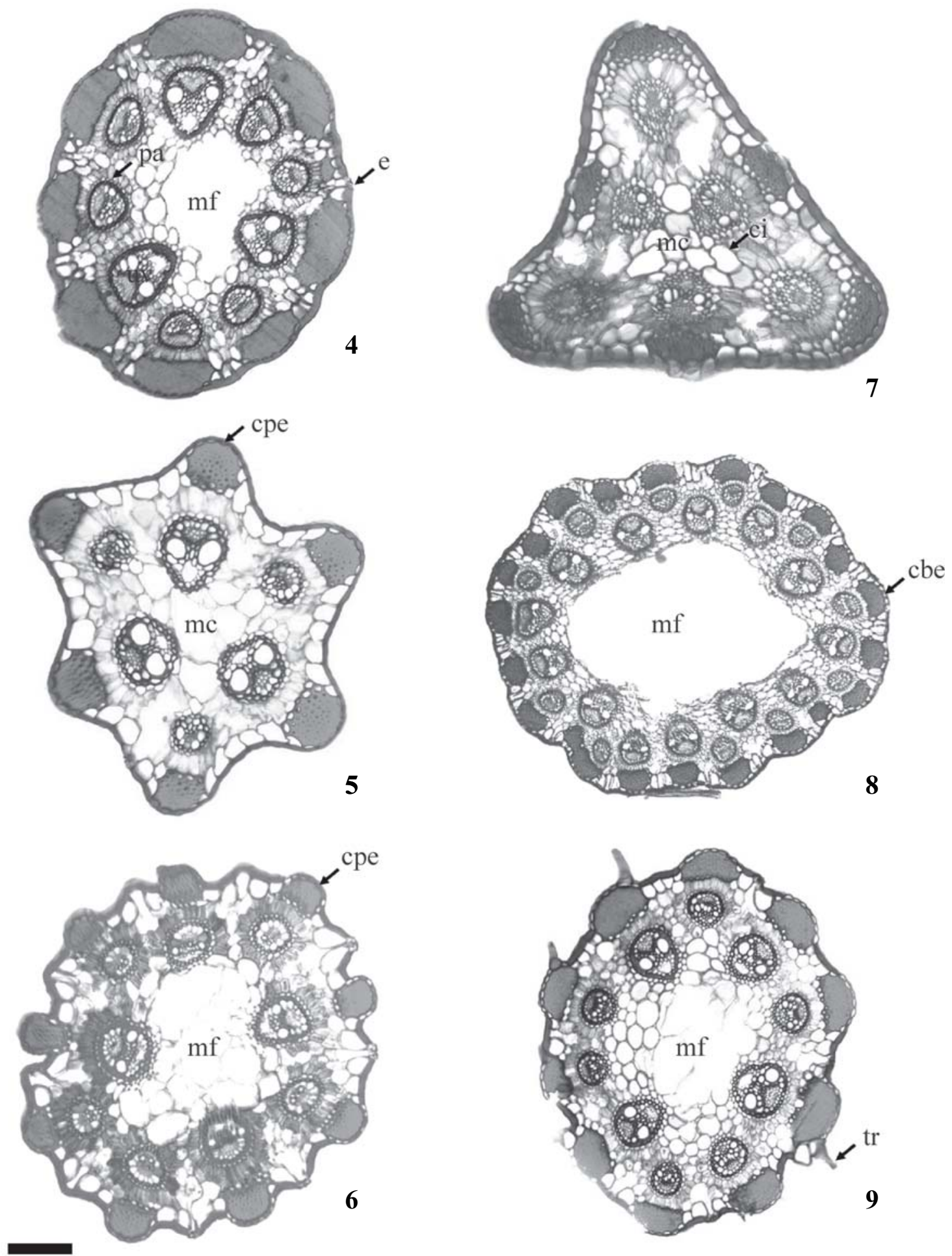

Figuras 4-9. Seção transversal do escapo de Bulbostylis. 4. B. sphaerocephala (Boeck.) C.B. Clarke. 5. B. tenuifolia (Rudge) Macbr. 6. B. smithii Barros. 7. B. splendens M.T. Strong. 8. B. jacobinae (Steud.) Lindm. 9. B. vestita (Kunth) C.B. Clarke. (ci= célula irregular; $\mathrm{cbe}=$ célula bem evidente; $\mathrm{cpe}=$ célula pouco evidente; $\mathrm{e}=$ estômato; $\mathrm{mc}=$ medula compacta; $\mathrm{mf}=$ medula fistulosa; $\mathrm{pa}=$ parênquima radiado; $\operatorname{tr}=$ tricoma; $\mathrm{uv}=$ unidade vascular ou monostelo). Barra $=45 \mu \mathrm{m}$.

Figure 4-9. Scape transverse section of Bulbostylis. 4. B. sphaerocephala (Boeck.) C.B. Clarke. 5. B. tenuifolia (Rudge) Macbr. 6. B. smithii Barros. 7. B. splendens M.T. Strong. 8. B. jacobinae (Steud.) Lindm. 9. B. vestita (Kunth) C.B. Clarke. (ci=irregular cells; cbe $=$ more evident cells; $\mathrm{cpe}=$ less evident cells; $\mathrm{e}=$ stomata $\mathrm{mc}=$ compact medulla; $\mathrm{mf}=$ fistulate medulla; $\mathrm{pa}=$ radiate parenchyma; $\operatorname{tr}=$ trichome; $u v=$ vascular unit or monostele). Bar $=45 \mu \mathrm{m}$. 
Os dados referentes ao escapo foram utilizados para uma possível aplicação taxonômica, considerando-se que o escapo de Bulbostylis apresenta unidades vasculares onde o periciclo corresponde à bainha Kranz, como demonstrado em Fimbristylis por Menezes et al. (2003). A presença da anatomia Kranz no escapo de Cyperaceae já foi observada por Estelita \& Handro (1987). Esses autores verificaram a presença da bainha Kranz no escapo de algumas espécies de Fimbristylis Vahl e Cyperus L., inclusive demonstrando ter origem procambial, mas não se referem a esse tecido como sendo o periciclo.

Alguns caracteres são comuns às espécies brasileiras de Bulbostylis analisadas, tais como: cutícula espessada e unidades vasculares menores completamente envolvidas por parênquima radiado na maioria das espécies e unidades vasculares de maior calibre com um envelope parenquimático crescentiforme. Essas características também foram consideradas comuns por Govindarajalu (1966) para os táxons sul-indianos de Bulbostylis.

A seção transversal do escapo de Bulbostylis é bastante variada (figuras 4-9), com predomínio da forma circular. Em alguns táxons ocorrem formas do tipo irregular (figura 5-6) ou triangular (figura 7). $\mathrm{O}$ formato irregular e a presença de algumas concavidades entre as unidades vasculares estão geralmente associados à ocorrência de costelas proeminentes nessas regiões (figuras 5-7).

A epiderme das espécies analisadas é unisseriada, revestida por cutícula espessada em todos os táxons, tendo sido observada a presença de hipoderme apenas em B. fendleri C.B. Clarke e B. lombardii Kral \& M. Strong (figura 10). As células epidérmicas, localizadas nas regiões entre as unidades vasculares, apresentam seu maior eixo perpendicular à superfície (células alongadas) ou paralelo à superfície (células achatadas) (figura 12). As células epidérmicas localizadas nas regiões das unidades vasculares podem ser bem evidentes ou pouco evidentes devido a diferenças em suas dimensões (figuras 5, 6, 8, 10, 15, 17, 18, 19). Tricomas tectores foram observados em Bulbostylis hirtella (Schrad.) Urb. e B. vestita (Kunth) C.B. Clarke (figura 9).

Os estômatos são do tipo paracítico, como já citado por Metcalfe (1971) e podem ocorrer ao nível das demais células epidérmicas ou em elevações (figuras 10-11, 13).

Depósito de sílica do tipo cônico foi observado na parede periclinal interna de Bulbostylis jacobinae (Steud.) Lindm. e B. hirtella (Schrad.) Urb. (figura 14), confirmando a ocorrência de corpos silicosos com vários formatos na tribo Scirpeae observada por Metcalfe (1969).

$\mathrm{O}$ esclerênquima ocorre na forma de cordões de fibras subepidérmicas que variam de oblongos a poligonais (figuras 4-19). Esses cordões estão geralmente associados aos feixes vasculares e, às vezes, a células que possuem tricoma (figura 9) e sílica (figura 14).

Metcalfe (1969) citou a presença de esclerênquima, principalmente na forma de feixes, e cordões de clorênquima com tendência à estrutura radiada entre alguns dos caracteres anatômicos de representantes da tribo Scirpeae.

O parênquima clorofiliano se apresenta radiado em torno das unidades vasculares que correspondem aos traços foliares na maioria das espécies (figuras 4-14, $16,18,19)$. O parênquima radiado envolve totalmente as menores unidades vasculares da maioria das espécies, que correspondem aos traços mais próximos de brácteas, e nas unidades maiores pode envolver de 50\% a $75 \%$ (figuras $6,10-12$ ). A organização do parênquima radiado, nas unidades vasculares maiores, pode ser utilizada como caráter diagnóstico entre alguns táxons.

As unidades vasculares estão organizadas em uma ou duas séries (figuras 4-9). As séries podem ser mais ou menos evidentes. As unidades vasculares aparecem em número, tamanho e posições variáveis. O número de unidades vasculares observadas por seção transversal variou de 4-25 (figuras 4-9). Na maioria das espécies, as unidades menores estão situadas na série externa (próximas ao córtex) e as de maior calibre na série interna (próximas à região medular) (figuras 4-9). Cada unidade vascular é circundada por três bainhas, que correspondem centrifugamente ao periciclo, ao mestoma (endoderme) e à bainha parenquimática. A mais externa possui cloroplastos e não é espessada, a intermediária corresponde à endoderme espessada e lignificada (mestoma) e a mais interna à bainha Kranz (periciclo) (figura 12). A bainha mestoma nas unidades maiores pode se apresentar completa ou incompleta, neste último caso interrompida por elementos traqueais de maior calibre. Nas unidades menores, o mestoma é contínuo (figuras 4,11). Além disso, pode ocorrer um tecido esclerênquimático no lado interno das unidades vasculares (figura 15).

A medula pode se apresentar compacta com células arredondadas ou irregulares, ou fistulosa (figuras 4, 9). Govindarajalu (1966) cita a presença de medula sólida composta por células parenquimáticas ampliadas em quatro espécies de Bulbostylis e medula sólida ou oca em Bulbostylis capillaris (L.) C.B. Clarke var. trifida (Nees) C.B. Clarke. Bruhl (1995) incluiu o caráter presença ou ausência de medula na lista de caracteres utilizados para a análise cladística e fenética com as Cyperaceae.

Segundo Metcalfe (1969), apesar da natureza da bainha vascular nas Scirpeae se apresentar bastante variável, a nível de gênero é constante, com exceção 

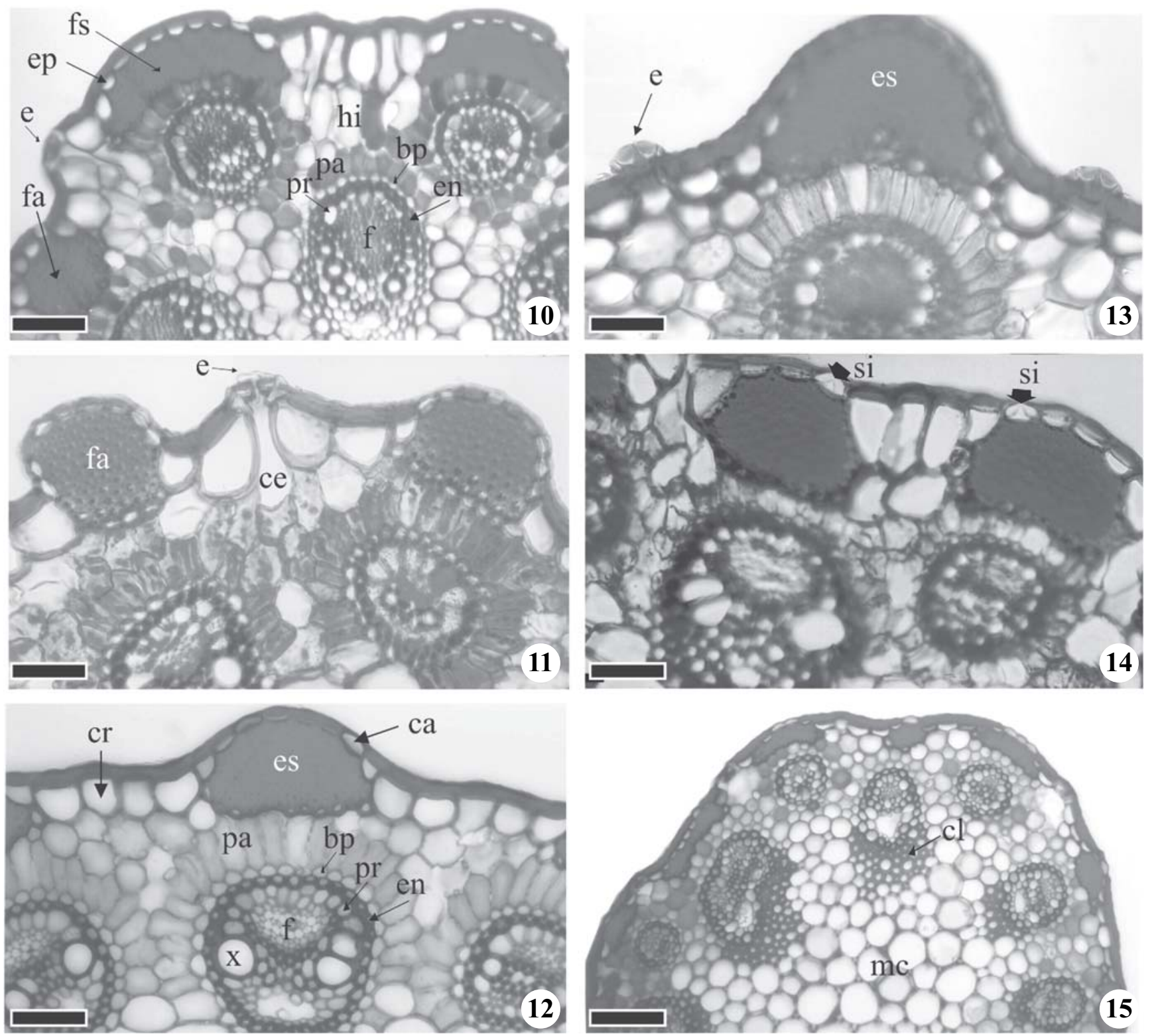

Figuras 10-15. Seção transversal do escapo de Bulbostylis. 10. B. lombardii Kral \& M.T. Strong. 11. B. smithii Barros. 12. B. scabra (Presl) C.B. Clarke. 13. B. fimbriata (Nees) C.B. Clarke. 14. B. jacobinae (Steud.) Lindm. 15. B. paradoxa (Spreng.) Lindm. (bp = bainha parenquimática; $\mathrm{ca}=$ célula achatada; $\mathrm{ce}=$ câmara subestomática; $\mathrm{cl}=$ células lignificadas; $\mathrm{cr}=\mathrm{célula}$ alongada; $\mathrm{e}=$ estômato; en = endoderme; ep = epiderme; es = esclerênquima; $\mathrm{f}=$ floema; fa $=$ feixes de esclerênquima arredondado; $f \mathrm{~s}=$ feixe de esclerênquima semiesférico; $\mathrm{hi}=$ hipoderme; $\mathrm{mc}=$ medula compacta; $\mathrm{pa}=$ parênquima radiado; $\mathrm{pr}=$ periciclo; $\mathrm{si}=$ corpo silicoso, $\mathrm{x}=$ xilema). Barra $=22 \mu \mathrm{m}$.

Figure 10-15. Scape transverse section of Bulbostylis. 10. B. lombardii Kral \& M.T. Strong. 11. B. smithii Barros. 12. B. scabra (Presl) C.B. Clarke. 13. B. fimbriata (Nees) C.B. Clarke. 14. B. jacobinae (Steud.) Lindm. 15. B. paradoxa (Spreng.) Lindm. (bp = parenchymatic sheath; $\mathrm{ca}=$ cell flattened; $\mathrm{ce}=$ substomatal chamber; $\mathrm{cl}=$ sclerenchyma fibers; $\mathrm{cr}=$ alongated cell; $\mathrm{e}=$ stomata; en = endodermis; $\mathrm{ep}=$ epidermis; es = sclerenchyma; $\mathrm{f}=$ phloem; fa = rounded sclerenchyma strand; $\mathrm{fs}=\mathrm{semispherical}$ sclerenchyma strand; $\mathrm{hi}=$ hypodermis; $\mathrm{mc}=$ compact medulla; $\mathrm{pa}=$ radiate parenchyma; $\mathrm{pr}=$ pericycle; $\mathrm{si}=$ sílica body, $\mathrm{x}=$ xylem). Bar $=22 \mu \mathrm{m}$. 
de Scirpus, que apresenta algumas espécies onde o periciclo é de difícil individualização, a endoderme é fibrosa (mestoma) e a bainha externa é parenquimática. Nos outros gêneros, o feixe é envolvido por três camadas, onde a interna (periciclo) e a externa são parenquimáticas, e a camada mediana constitui o mestoma, como observadas em Bulbostylis, Nelmesia e Fimbristylis (Menezes et al. 2003). A organização e a natureza das bainhas foliares descritas para a tribo Scirpeae (Metcalfe 1971) corresponde à observada nas espécies de Bulbostylis estudadas neste trabalho.

Soros e Bruhl (2000) classificaram o gênero Bulbostylis, quanto ao tipo de anatomia foliar, como $\mathrm{C}_{4}$. De acordo com as análises realizadas, as espécies estudadas foram classificadas como $\mathrm{C}_{4}$, sendo subdivididas em dois grupos, espécies com parênquima radiado e com parênquima não radiado (figuras 4, 12, 15, 19). Esses dois tipos de anatomia foliar foram anteriormente descritos como "fimbristylóide e eleocharóide", respectivamente. No tipo "fimbristylóide", as unidades vasculares são circundadas por três bainhas, que correspondem respectivamente ao PCR (periciclo), ao mestoma (endoderme) e à bainha parenquimática externa, com o periciclo correspondendo à bainha Kranz. No tipo "eleocharóide", as unidades vasculares estão circundadas por duas bainhas, que correspondem ao periciclo e ao mestoma. Soros \& Bruhl (2000) referiram, em Cyperaceae, a ocorrência de mais do que um tipo anatômico $\mathrm{C}_{4}$ em alguns gêneros, confirmando o resultado observado nas espécies de Bulbostylis analisadas no presente trabalho.

Os caracteres da anatomia do escapo, tais como o formato em seção transversal, a presença de costelas e sulcos, que definem o tipo de seção transversal, o aspecto das células epidérmicas e estômatos, a forma dos cordões esclerenquimáticos corticais, o número de unidades vasculares, a presença de medula fistulosa e a ocorrência de parênquima radiado, permitem o diagnóstico específico dos táxons estudados segundo a chave a seguir.
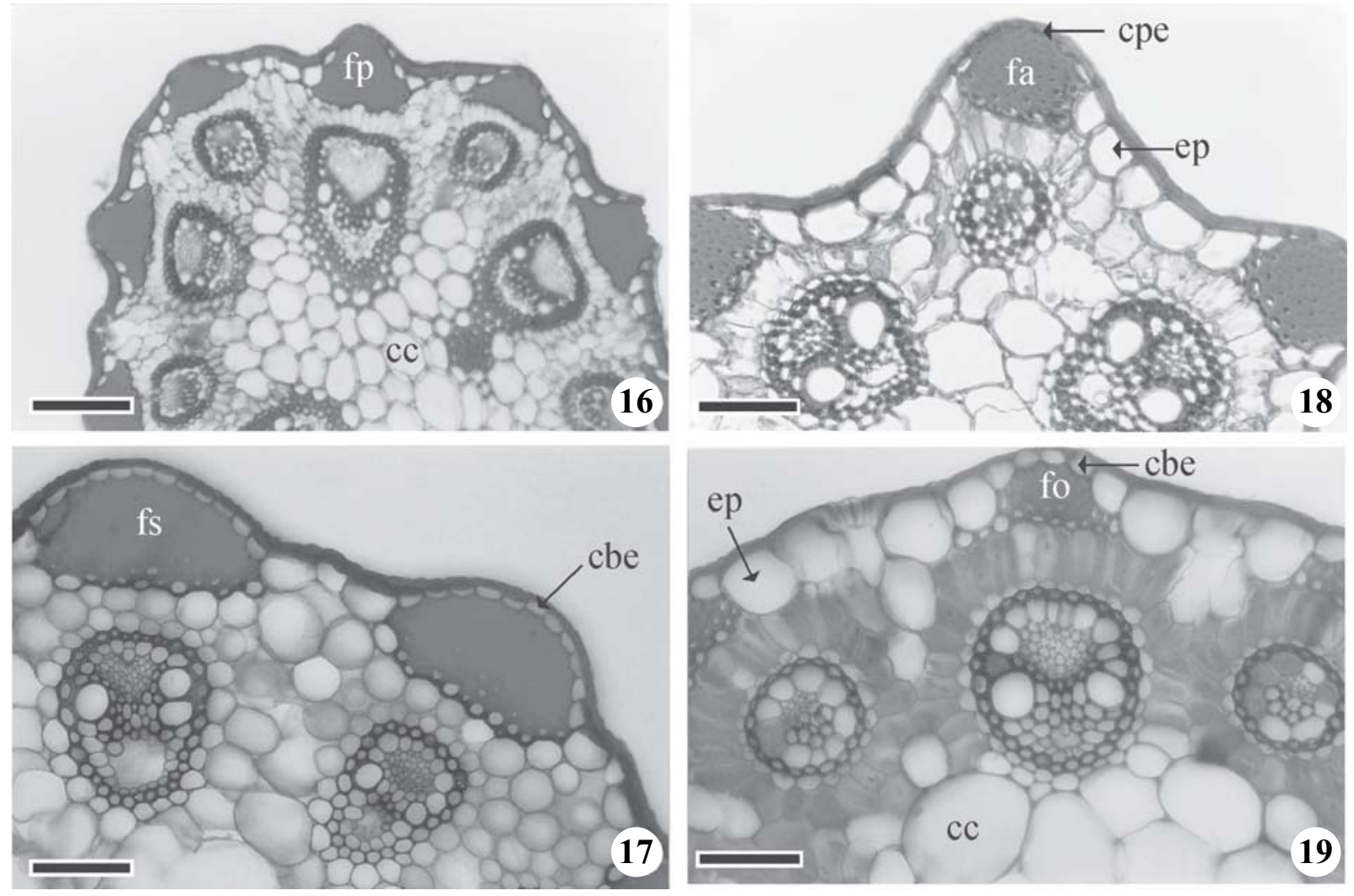

Figuras 16-19. Seção transversal do escapo de Bulbostylis. 16. B. nesiotis C.B. Clarke 17. B. conifera (Kunth) C.B. Clarke 18. B. tenuifolia (Rudge) J.F. Macbr. 19. B. juncoides ((Vahl) Kuk. (cbe = célula bem evidente; cc = célula circular; cpe = célula pouco evidente; $\mathrm{ep}=$ epiderme; $\mathrm{fa}=$ feixe arredondado; $\mathrm{fp}=$ feixe poligonal, fo = feixe oblongo; $\mathrm{fs}=$ feixe semiesférico). $\mathrm{Barra}=22 \mu \mathrm{m}$.

Figure 16-19. Scape transverse section of Bulbostylis. 16. B. nesiotis C.B. Clarke 17. B. conifera (Kunth) C.B. Clarke 18. B. tenuifolia (Rudge) J.F. Macbr. 19. B. juncoides ((Vahl) Kuk. (cbe = more evident cells; cc $=$ rounded cells; $c$ e $=$ less evident cells; ep = epidermis; fa = rounded sclerenchyma strand; fp = polygonal sclerenchyma strand; fo = oblong sclerenchyma strand; fs $=$ semispherical sclerenchyma strand). Barra $=22 \mu \mathrm{m}$. 
Chave de identificação das espécies de Bulbostylis usando caracteres estruturais do escapo:

1. Seção transversal do escapo triangular.

B. splendens

1. Seção transversal do escapo circular ou irregular

2. Seção transversal do escapo circular

3. Hipoderme presente

B. fendleri

3. Hipoderme ausente

4. Parênquima radiado ausente

B. conifera

4. Parênquima radiado presente

5. Estômatos em elevações

6. Cordões esclerenquimáticos apenas semiesféricos na seção transversal ....... B. eleocharoides

6. Cordões esclerenquimáticos semiesféricos e arredondados na mesma seção transversal

B. juncoides

5. Estômatos ao nível das células epidérmicas

7. Até 20 unidades vasculares por seção transversal

8. Cordões esclerenquimáticos com duas formas diferentes na mesma espécie

B. sphaerocephala

8. Cordões esclerenquimáticos de uma única forma na mesma espécie

9. Cordões esclerenquimáticos semiesféricos

10. Costelas ausentes

11. Seção transversal com 5 cordões esclerenquimáticos

B. capillaris

11. Seção transversal com 10 cordões esclerenquimáticos B. sp. 2

10. Costelas presentes

12. Seção transversal com 6 cordões esclerenquimáticos

B. arenaria

12. Seção transversal com 8 cordões esclerenquimáticos

B. major

9. Cordões esclerenquimáticos arredondados

13. Seção transversal com 11 cordões esclerenquimáticos

B. junciformis

13. Seção transversal com 15 cordões esclerenquimáticos

B. lanata

7. De 21a 27 unidades vasculares por seção transversal do escapo

14. Cordões esclerenquimáticos de uma única forma na mesma espécie

B. latifolia

14. Cordões esclerenquimáticos com duas formas diferentes na mesma espécie

15. Cordões esclerenquimáticos oblongos e arredondados

16. Seção transversal do escapo com 17 cordões esclerenquimáticos

B. consanguinea

16. Seção transversal do escapo com 22 cordões esclerenquimáticos ....... jacobinae

15. Cordões esclerenquimáticos semiesféricos e poligonais ou semiesféricos

e arredondados

17. Cordões esclerenquimáticos semiesféricos e poligonais, 22 cordões esclerenquimáticos por seção transversal

B. amambayensis

17. Cordões esclerenquimáticos semiesféricos e arredondados, 25 cordões esclerenquimáticos por seção transversal

B. svensoniana

2. Seção transversal do escapo irregular

18. Cordões esclerenquimáticos arredondados

19. Estômatos ao nível da epiderme

B. paraensis

19. Estômatos em elevações B. sellowiana

18. Cordões esclerenquimáticos semiesféricos

20. Seção transversal do escapo irregular tendendo a triangular

21. Unidades vasculares organizadas em duas séries

B. carajana

21. Unidades vasculares organizadas em uma série 
22. Seção transversal do escapo com 5 cordões esclerenquimáticos

B. loefgrenii

22. Seção transversal do escapo com 9 cordões esclerenquimáticos

B. sellowiana

20. Seção transversal do escapo irregular, tendendo a circular

23. Seção transversal com 11-15 cordões esclerenquimáticos

24. Cordões esclerenquimáticos com duas formas diferentes na mesma espécie

24. Cordões esclerenquimáticos de uma única forma (semiesféricos ou poligonais) na mesma espécie

25. Tecido esclerenquimático no lado interno das unidades vasculares presente

B. fasciculata

25. Tecido esclerenquimático no lado interno das unidades vasculares ausente

26. Estômatos em elevações

B. fimbriata

26. Estômatos ao mesmo nível das células epidérmicas

27. Diferentes números de unidades vasculares e cordões esclerenquimáticos

B. paradoxa

Mesmo número de unidades vasculares e cordões esclerenquimáticos

28. Células da medula irregulares

B. pachypoda

28. Células da medula arredondadas

29. Presença de fibras no lado interno das unidades vasculares

B. nesiotis

29. Ausência de fibras no lado interno das unidades vasculares

B. scomburgkiana

23. Seção transversal com 6-10 cordões esclerenquimáticos

30. Tricomas tectores presentes

B. vestita

30. Tricomas tectores ausentes

31. Medula fistulosa

B. conspicua

31. Medula não fistulosa

32. Estômatos em elevações

33. Cordões esclerenquimáticos de dois tipos em seção transversal

(oblongo e arredondado)

B. lombardii

33. Cordões esclerenquimáticos de um único tipo

34. Cordões esclerenquimáticos poligonais

B. smithii

34. Cordões esclerenquimáticos arredondados

35. Número de unidades vasculares e cordões esclerenquimáticos diferentes

B. edwalliana

35. Mesmo número de unidades vasculares e cordões esclerenquimáticos

B. hirtella

32. Estômatos ao nível das células epidérmicas

36. Cordões esclerenquimáticos semiesféricos

37. Células da medula irregulares

B. distichoides

37. Células da medula arredondadas

38. Seção transversal com 7 cordões esclerenquimáticos

B. lagoensis

38. Seção transversal com 9 cordões esclerenquimáticos

B. scabra

36. Cordões esclerenquimáticos oblongos ou arredondados

39. Cordões esclerenquimáticos oblongos

B. truncata

39. Cordões esclerenquimáticos arredondados

40. Seção transversal com 6 cordões esclerenquimáticos

B. tenuifolia

40. Seção transversal com 7 cordões

esclerenquimáticos

Bulbostylis sp. 1 
Agradecimentos - A primeira autora agradece à Fapesp pela concessão da bolsa de doutorado (Processo 99/03773-1).

\section{Referências Bibliográficas}

ALVES, M.V. 2000. Abordagem tipológica das inflorescências em monocotiledôneas. In Tópicos Atuais em Botânica (T.B. Cavalcanti, B.M.T. Walter, G.P. Silva, A.E. Ramos, J.F. Ribeiro, M.C. Silva, R.B.N. Alves \& T.A.B. Alves, coords). Embrapa, Brasília, p.17-22.

ALVES, M.V., ESTELITA, M.E.M., WANDERLEY, M.G.L. \& THOMAS, W.W. 2002. Aplicações taxonômicas da anatomia foliar das espécies brasileiras de Hypolytrum Rich. (Cyperaceae). Revista Brasileira de Botânica 25:19.

ARAÚJO, A.C. \& LONGHI-WAGNER, H.M. 1997. Anatomia foliar e micromorfologia do fruto na taxonomia de Cyperus L. (Cyperaceae). Iheringia 48:103-120.

ARRUDA, R.C.O \& NEVES, L.J. 2005. Leaf anatomy of Trilepis lhotzkiana Nees and Trilepis ciliatifolia T. Koyama (Cyperaceae) Juss. Acta Botanica Brasilica, 19:889-897.

BREBNER, G. 1902. On the anatomy of Danaea and other Marattiaceae. Annals of Botany 16: 517-552.

BRUHL, J.J. 1995. Sedge genera of the world: relationships and a new classification of the Cyperaceae. Australian Systematic Botany 8:125-305.

CHEADLE, V. \& UHL, N. 1948. Types of vascular bundles in the Monocotyledoneae and their relation to the late metaxylem conducting elements. American Journal of Botany 35:486-496.

DENTON, M.F. 1983. Anatomical studies of the Luzulae Group of Cyperus (Cyperaceae). Systematic Botanic 8:250-262.

EITEN, L.T. 1969. The vegetative anatomy of Eleocharis interstincta (Vahl) Roem. \& Schult. Arquivos de Botânica do Estado de São Paulo 4:187-228.

ESAU, K. 1977. Plant anatomy. John Wiley \& Sons, New York.

ESTELITA, M.E.M. 1992. Origin and structure of the Kranz tissues in Cyperaceae. Boletim de Botânica da Universidade de São Paulo 13:41-48.

ESTELITA, M.E.M. 1993. Anatomia dos órgãos vegetativos de Remirea maritima Aubl. (Cyperaceae). Naturalia 18:123-134.

ESTELITA, M.E.M. 1999. Estudos morfológicos em Cyperaceae. Tese de Livre Docência. Instituto de Biociências, Universidade de São Paulo.

ESTELITA, M.E.M. \& HANDRO, W. 1987. Kranz pattern in leaf, scape and bract of Cyperus and Fimbristylis species. Revista Brasileira de Botânica 10:105-111.

FAHN, A. 1989. Plant anatomy. Pergamon Press, São Paulo.

FONTQUER, P. 1989. Diccionário de Botánica. Editorial Labor, Barcelona.

FOSTER, A.S. \& GIFFORD, E.M. 1959. Comparative morphology of vascular plants. W.H. Freeman, San Francisco.
GOETGHEBEUR, P. 1986. Genera Cyperacearum, Een bijdrage tot de kennis van de morfologie, systematiek en fylogenese van de Cyperacae-genera. PhD thesis, University of Gent, Gent.

GOVINDARAJALU, E. 1966. The systematic of South Indian Cyperaceae: Bulbostylis Kunth. Journal of Linnean Society 59:289-304.

GOVINDARAJALU, E. 1969a. The systematic anatomy of South Indian Cyperaceae: Cyperus L. subgen. Kyllinga (Rottb.) Suringar. Journal of Linnean Society 62:41-58.

GOVINDARAJALU, E. 1969b. The systematic anatomy of South Indian Cyperaceae: Fuirena Rottb. Journal of Linnean Society 62:27-40.

GOVINDARAJALU, E. 1974. The systematic anatomy of South Indian Cyperaceae: Cyperus L. subgen. Juncellus, Cyperus subgen. Mariscus and Lipocarpha R.Br. Botanical Journal of the Linnean Society 68:235-266.

GOVINDARAJALU, E. 1981. Studies in Cyperaceae - XIX. Novelty in Lipocarpha: L. raynaleana and its vegetative anatomy. Adansonia, serie 2, 20:369-375.

HOLMGREN, P.K., HOLMGREN, N.H. \& BARNETT, L.G. 1990. Index Herbarium. Part 1: The Herbaria of the World. $8^{\text {th }}$ ed. New York Botanical Garden, New York.

JOHANSEN, D. 1940. Plant microtechnique. McGraw-Hill Book Co., New York.

KOYAMA, T. 1965. Interrelationships between the tribes Lagenocarpeae and Sclerieae (Cyperaceae). Bulletin of the Torrey Botanical Club 92:250-265.

KOYAMA, T. 1967. The systematic significance of leaf structure in the Tribe Sclerieae (Cyperaceae). Memoirs of the New York Botanical Garden 16:46-70.

KOYAMA, T. \& MAGUIRE, B. 1965. Cyperaceae. Tribe Lagenocarpeae. Memoirs of the New York Botanical Garden 12:8-19.

KRAUS, J. \& ARDUIN, M. 1997. Manual básico de métodos em morfologia vegetal. Edur, Seropédica.

KUKKONEN, I. 1967. Vegetative anatomy of Uncinia (Cyperaceae). Annals of Botany 31:523-544.

LYE, K.A. 1996. A New subspecies of Bulbostylis hispidula (Cyperaceae) from Somalia, Willdenowia 25:595-600.

MENEZES, N.L. de, SILVA, D.C., ARRUDA, R.C.O., MELODE-PINNA, G.F., CARDOSO, V.A., CASTRO, N.M., SCATENA, V.L. \& SCREMIN-DIAS, E. 2005. Meristematic activity of the endodermis and the pericycle in the primary thickening in monocotyledons. Considerations on the "PTM'. Anais da Academia Brasileira de Ciências 77:259-274.

MENEZES, N.L. de, SILVA, D.C., \& MELLO DE PINA, G.F. 2003. Folha. In Anatomia Vegetal (B. Appezzato-daGlória \& S.M. Carmello-Guerreiro, eds.). Universidade Federal de Viçosa. Viçosa, p. 303-329.

METCALFE, C.R. 1969. Anatomy as an aid to classifying the Cyperaceae. American Journal of Botany 56:782-790.

METCALFE, C.R. 1971. Anatomy of the monocotyledons, Cyperaceae, v.5. Clarendon Press, Oxford. 
METCALFE, C.R. \& CHALK, L. 1950. Anatomy of the Dicotyledons. Clarendon Press, Oxford.

METCALFE, C.R. \& GREGORY, M. 1964. Comparative anatomy of Monocotyledons: Some new descriptive terms for Cyperaceae with a discussion of variations in leaf form noted in the family. Notes Jodrell Laboratory 1:1-11.

MUASYA, A.M., BRUHL, J.J., SIMPSON, D.A, CULHANM, A. \& CHASE, M.W. 2000. Suprageneric phylogeny of Cyperaceae: a combined analysis. In Monocots systematics and evolution. (K.L. Wilson \& D.A. Morrison eds.) CSIRO Publishing, Melbourne, p. 593-601.

OGURA, Y. 1972. Comparative anatomy of vegetative organs of the pteridophytes $-2^{\text {nd }}$ ed. Gebrüder Bont Reager, Berlin.

OH, Y.C. 1992. Leaf epidermal patterns of Korean sedge taxa characterized by SEM (V. Bulbostylis, Eriophorum, Fuirena, Kyllinga, Lipocarpha, Pycreus, Rynchospora and Scleria). The Journal of Basic Science 9:27-41.

PLOWMAN, A.B. 1906. The comparative anatomy and phylogeny of the Cyperaceae. Annals of Botany 20:1-33.

PRATA, A.P. 2004. O gênero Bulbostylis Kunth (Cyperaceae) no Brasil. Tese de doutorado, Universidade de São Paulo, São Paulo.

PFEIFFER, H. 1927. Untersuchungen zur vergleichenden anatomie der Cyperacceen I. Die Anatomie der Blatter. Beihefte zum Botanischen Centralblatt 44:90-176.

ROCHA, E.A. 2002. Estudo taxonômico de Rhynchospora Val Seção Tenues (Cyperaceae) no Brasil. Hoehnea 29(3): 189-214.

RODRIGUES, A.C. \& ESTELITA, M.E.M. 2003. Origin and structure of the Kranz tissue in bracts of Cyperus giganteus Vahl (Cyperaceae). Revista Brasileira de Botânica 26:445-452.
SASS, J. 1951. Botanical microtechnique. The Iowa State College Press, Iowa.

SAJO, M.G. \& CASTRO, N.M. 2003. Caule. In Anatomia vegetal (B. Apezzato -da- Glória \& S.M. CarmelloGuerrreiro, eds.). Viçosa, UFV p 283-302.

SHARMA, O.P. \& MEHRA, P.N. 1972. Systematic anatomy of Fimbristylis Vahl (Cyperaceae). Botanical Gazette 133:87-95.

SHEPHERD, G.J. 1976. The use of anatomical characters in the intrageneric classification of Carex (Cyperaceae). Hoehnea 6:33-54.

SILVA, D.C. 2000. Anatomia dos órgãos vegetativos de Lagenocarpus Nees (Cyperaceae) da Serra do Cipó MG. Tese de doutorado, Universidade de São Paulo, São Paulo.

SMITH, G.M. 1955. Cryptogamic Botany. vol. II, Bryophytes and Pteridophytes. $2^{\text {nd }}$ ed. Mcgraw-Hil, New Cork.

SOROS, C. \& BRUHL, J. 2000. Multiple evolutionary origins of $\mathrm{C}_{4}$ photosynthesis in Cyperaceae. In Monocots: systematics and evolution (K.L. Wilson \& D. Morison, eds.). CSIRO Publishing, Melbourne, p.629-636.

STANDLEY, L.A. 1990. Anatomical aspects of the taxonomy of sedges (Carex, Cyperaceae). Canadian Journal of Botany 68:1449-1456.

VAN TIEGHEM, P.H. 1898. Èlements de Botanique. I Botanique Générale. $3^{\text {éme }}$ ed. Mason et Cie, Paris.

VITTA, F.A. 2005. Revisão taxonômica e estudos morfológicos e biossistemáticos em Cryptangium Schrad. ex Nees e Lagenocarpus Nees. Cyperaceae: Cryptangieae. Tese de doutorado, Universidade Estadual de Campinas - Unicamp. São Paulo. 